\title{
Left ventricular mechanical dyssynchrony in patients with coronary artery disease
}

\author{
Nili Zafrir, MD, FESC \\ a Department of Cardiology, Rabin Medical Center, Petah Tikva, Israel \\ Received Jan 14, 2016; accepted Jan 14, 2016 \\ doi:10.1007/s12350-016-0416-4
}

\section{See related article, pp. 482-490}

The use of phase analysis from gated SPECT myocardial perfusion imaging (MPI) for the evaluation of left ventricular mechanical dyssynchrony (LVMD) was introduced by Chen and Garcia ${ }^{1}$ in 2005 . In patients with coronary artery disease (CAD), the need to assess resynchronization arises in the presence of systolic heart failure when another solution for left ventricular treatment in addition to heart failure medications is needed. Although device-based solutions, such as cardiac resynchronization therapy (CRT) and implantable cardioverter-defibrillator (ICD) therapy, has been found to improve symptoms of heart failure and reduce overall mortality, the lack of a beneficial response was reported in a substantial number of patients. ${ }^{2}$ Current indications for CRT are NYHA class 3-4, LVEF $\leq 35 \%$, left bundle branch block or QRS width $>120 \mathrm{~ms}$. However, LVMD is not included, although it has been recognized for more than 10 years. A considerable number of studies have shown that high values of phase standard deviation (SD) and/or phase histogram bandwidth (BW) indicate LVMD, and that they can assist clinicians in the selection of patients for CRT. Furthermore, LVMD may serve as a predictive factor of both cardiac outcome and all-cause mortality. ${ }^{3-6}$

LVMD has been studied in various clinical subsets, including patients with systolic LV dysfunction, such as ischemic and nonischemic cardiomyopathy, ${ }^{7-9}$ and patients with end-stage renal failure and on chemotherapy, in whom LVMD was found to be a useful

Reprint requests: Nili Zafrir, MD, FESC, Department of Cardiology, Rabin Medical Center, Beilinson Campus, Petah Tikva, Israel; zafrirmd@isdn.net.il

J Nucl Cardiol 2017;24:491-3.

$1071-3581 / \$ 34.00$

Copyright (C) 2016 American Society of Nuclear Cardiology. prognosticator. ${ }^{10-12}$ Others investigated the yield of LVMD as part of gated SPECT in consecutive unselected patients with suspected CAD or known CAD who were referred for evaluation of ischemia. The findings showed that LVMD has value as an independent predictor of cardiac outcome, in addition to $\mathrm{LV}$ ejection fraction (LVEF) and perfusion defects. ${ }^{13,14}$

The article by Hess et $\mathrm{al}^{15}$ in this issue of the Journal of Nuclear Cardiology reports the study of LVMD in a large group of patients $(n=1244)$ with CAD who underwent gated SPECT MPI in 1993-1999. Phase analysis assessment was done retrospectively in the patients in whom at least one major epicardial CAD was documented. The cohort was followed for all-cause death and cardiac death. At 8 years, LVMD showed a stronger relationship with outcome than electrical dyssynchrony measured by QRS duration. After adjustment for baseline characteristics and continuous measured LVEF, neither mechanical nor electrical dyssynchrony was independently associated with allcause death or cardiac death. However, among patients with LVEF > 35\%, mechanical and electrical dyssynchrony together had a prognostic value above that afforded by LVEF alone $(P=.0181)$.

This study has 2 merits. First, it studied the value of LVMD in a large group of patients with CAD and showed that a high histogram BW is more strongly associated with mortality than QRS. Hess et $\mathrm{al}^{15}$ graphically demonstrated the distribution of phase BWs in the CAD population and analyzed the presence of $\mathrm{LV}$ dyssynchrony by BW values of more or less than $100^{\circ}$. They found an incremental association between clinical variables, QRS duration, LBBB, and all-cause or cardiovascular death as indicated by global Chi-square in serial multivariable models $(P>.0001)$.

The second merit of the study is the finding that histogram BW may serve as an independent predictor of mortality in patients with CAD and LVEF $>35 \%$. Furthermore, on multivariate analysis, after adjusting for clinical characteristics, sequential models indicated that 
Table 1. Prognostic studies of LV dyssynchrony by phase SD and histogram BW in different populations with different LVEF values

\begin{tabular}{|c|c|c|c|c|c|}
\hline Study & Population No./indication* & LVEF (\%) & $\operatorname{SD}\left({ }^{\circ}\right)$ & BW $\left({ }^{\circ}\right)$ & Prediction \\
\hline Aljaroudi et $\mathrm{al}^{9}$ & $72 / I C D$ & $<40$ & 60 & 185 & Death or shock \\
\hline Uebleis et $\mathrm{al}^{8}$ & $135 / C A D$ & 38 & 24 & 63 & Death \\
\hline Goldberg et $\mathrm{al}^{7}$ & 324/NICMO & $35-50$ & 23 & & Death \\
\hline Pazhenkottil et al ${ }^{13}$ & 202/unselected ${ }^{\dagger}$ & 58 & 24 & 62 & MACE \\
\hline Zafrir et $\mathrm{al}^{14}$ & $787 /$ unselected $^{\dagger}$ & $62-44$ & 40 & & MACE \\
\hline Aggarwal et al ${ }^{11}$ & 828/ESRD & 55 & $\geq 21$ & $>56$ & Death \\
\hline Zafrir et $\mathrm{al}^{6}$ & 143/ICD/CRTD & $\leq 35$ & 60 & & MACE \\
\hline Hess et al ${ }^{15}$ & $1244 / C A D$ & 62 & 52 & $>100$ & Death \\
\hline
\end{tabular}

$L V$, Left ventricular; $S D$, standard deviation; $B M$, bandwidth; $L V E F$, left ventricular ejection fraction; $C A D$, coronary artery disease; NICMO, nonischemic cardiomyopathy; ICD, implantable cardioverter-defibrillator; CRTD, cardiac resynchronization therapy device; $M A C E$, major cardiac event.

* Indication for SPECT MPI.

${ }^{\dagger}$ Unselected patients referred for MPI.

BW was more strongly associated with all-cause death than phase SD (192.8 vs 188.1, global Chi square).

This study has some limitations. (1) The correlation of severity of CAD and LVMD was not demonstrated. It seems from the numerical data that patients with 3 vessel disease had more $\mathrm{LVMD}$ of $\mathrm{BW} \geq 100$ than patients with $\mathrm{BW}<100$ (43.9\% vs $34.6 \%$ ) compared to patients with 1 or 2 vessel disease ((65.4\% vs $67.8 \%)$ who had similar LVMD. It is also suggested that most of this population underwent intervention (percutaneous coronary intervention, coronary artery bypass graft) which could influence outcome, but these data were not provided. (2) No data regarding ischemia are presented, as expected from a SPECT MPI study, and as such, they were not included in the univariate analysis. (3) On analysis of the adjusted outcome, the authors included among the clinical variables also history of congestive heart failure but not NYHA classification, which is known to be the most powerful predictor of mortality. Additionally, as concluded in the study, patients with $\mathrm{CAD}$ found to have a $\mathrm{BW}$ above $100^{\circ}$ might have a worse prognosis regardless, owing to other variables such as burden of ischemia and infarct size.

Although both phase SD and BW contribute to the prediction of adverse outcome, the optimal LVMD values correlating with prognosis or therapy are inconsistent, varying in the different studies from $24^{\circ}$ to $60^{\circ}$ for $\mathrm{SD}$ and from $60^{\circ}$ to $185^{\circ}$ for $\mathrm{BW}$, irrespective of the presence of CAD (Table 1). The reasons are related to selection of the patient population and to different values of LV function (LVEF). As such, it seems that for predictive purposes, different cutoff values for LVMD need to be defined according to normal or abnormal range of LV function.
To summarize, every patient referred for gated SPECT, whether for diagnosis of CAD or with known $\mathrm{CAD}$, may benefit from the comprehensive assessment of perfusion, function, and dyssynchrony in one study. Combination of the LVMD values with a correlation to $\mathrm{CAD}$, as shown by Hess et al, ${ }^{15}$ may provide better information regarding prognosis and better assist clinicians in therapeutic decision-making between devicebased therapy, in cases of LV dysfunction, or improved medical treatment.

\section{References}

1. Chen J, Garcia EV, Folks RD, Cooke CD, Faber TL, Tauxe EL, et al. Onset of left ventricular mechanical contraction as determined by phase analysis of ECG-gated myocardial perfusion SPECT imaging: Development of a diagnostic tool for assessment of cardiac mechanical dyssynchrony. J Nucl Cardiol 2005;12:687-95.

2. Bax JJ, Gorcsan J 3rd. Echocardiography and noninvasive imaging in cardiac resynchronization therapy: Results of the PROSPECT (Predictors of Response to Cardiac Resynchronization Therapy) study in perspective. J Am Coll Cardiol 2009;53:1933-43.

3. Henneman MM, Chen J, Dibbets-Schneider P, Dibbets-Schneider P, Stokkel MP, Bleeker GB, et al. Can LV dyssynchrony as assessed with phase analysis on gated myocardial perfusion SPECT predict response to CRT? J Nucl Med 2007;48:1104-11.

4. Boogers MM, Van Kriekinge SD, Hennemam MM, Ypenburg C, Van Bommel RJ, Boersma E, et al. Quantitative gates SPECT derived phase analysis on gated myocardial perfusion SPECT detects left ventricular dyssynchrony and predicts response to cardiac resynchronization therapy. J Nucl Med 2009;50:718-25.

5. Samad Z, Atchley AE, Trimble MA, Sun JL, Shaw LK, Pagnanelli $\mathrm{R}$, et al. Prevalence and predictors of mechanical dyssynchrony as defined by phase analysis in patients with left ventricular dysfunction undergoing gated SPECT myocardial perfusion imaging. J Nucl Cardiol 2011;18:24-30.

6. Zafrir N, Bental T, Strasberg B, Solodky A, Mats I, Gutstein A, et al. Yield of left ventricular dyssynchrony by gated spect MPI in 
patients with heart failure prior to implantable cardioverter defibrillator or cardiac resynchronization therapy with a defibrillator: Characteristics and prediction of cardiac outcome. J Nucl Cardiol 2015. doi:10.1007/s12350-015-0310-5.

7. Goldberg AS, Alraies MC, Cerqueira MD, Jaber WA, Aljaroudi WA. Prognostic value of left ventricular mechanical dyssynchrony by phase analysis in patients with non-ischemic cardiomyopathy with ejection fraction 35-50\% and QRS $<150 \mathrm{~ms}$. J Nucl Cardiol 2014;21:57-66.

8. Uebleis C, Hellweger S, Laubender RP, Becker A, Shon HY, Lehner $\mathrm{S}$, et al. Left ventricular dyssynchrony assessed by gated SPECT phase analysis in an independent predictor of death in patients with advanced coronary artery disease and reduced left ventricular function not undergoing cardiac resynchronization therapy. Eur J Nucl Med Mol Imaging 2012;39:1561-9.

9. Aljaroudi WA, Hage FG, Hermann D, Doppalapudi H, Venkatarama R, Heo J, Iskandrian AE, et al. Relation of left ventricular dyssynchrony by phase analysis of gated SPECT images and cardiovascular events in patients with implantable cardiac defibrillators. J Nucl Cardiol 2010;17:298-304.

10. Aljaroudi W, Aggarwal H, Venkataraman R, Heo J, Iskandrian AE, Hage FG. Impact of left ventricular dyssynchrony by phase analysis on cardiovascular outcomes in patients with end-stage renal disease. J Nucl Cardiol 2010;17:1058-64.
11. Aggarwal H, AlJaroudi WA, Mehta S, Mannon R, Heo J, Iskandrian $\mathrm{AE}$, et al. The prognostic value of left ventricular mechanical dyssynchrony using gated myocardial perfusion imaging in patients with end-stage renal disease. J Nucl Cardiol 2014;21:739-46.

12. Thavendiranathan P, Poulin F, Lim KD, Plana JC, Woo A, Marwick TH. Use of myocardial strain imaging by echocardiography for the early detection of cardiotoxicity in patients during and after cancer chemotherapy: A systematic review. J Am Coll Cardiol 2014;63:2751-632768.

13. Pazhenkottil AP, Buechel RR, Husmann L, Nkoulou RN, Wolfrum $\mathrm{M}$, Ghadri JR, et al. Long-term prognostic value of left ventricular dyssynchrony assessment by phase analysis from myocardial perfusion imaging. Heart 2011;97:33-7.

14. Zafrir N, Nevzorov R, Bental T, Strasberg B, Gutstein A, Mats I, et al. Prognostic value of left ventricular dyssynchrony by myocardial perfusion gated SPECT in patients with normal and abnormal left ventricular function. J Nucl Cardiol 2014;21:532-40.

15. Hess P, Shaw L, Fudim M, Iskandrian A, Borges-Neto S. The prognostic value of mechanical left ventricular dyssynchrony defined by phase analysis from gated single photon emission computed tomography myocardial perfusion imaging among patients with coronary heart disease. J Nucl Cardiol 2016. doi: 10.1007/s12350-016-0423-5. 